\title{
Effective green equivalent-A measure of public green spaces for cities
}

\author{
Liang Yao, Jingru Liu*, Rusong Wang, Ke Yin, Baolong Han \\ State Key Laboratory of Urban and Regional Ecology, Research Center for Eco-Environmental Sciences, Chinese Academy of Sciences, 18 Shuangqing Road, \\ Haidian District, Beijing 100085, China
}

\section{A R T I C L E I N F O}

\section{Article history:}

Received 23 December 2013

Received in revised form 30 May 2014

Accepted 8 July 2014

\section{Keywords:}

Public green spaces

Normalized difference vegetation index

Accessibility

Gini coefficient

Beijing

\begin{abstract}
A B S T R A C T
Quantifying the public green space required by urban residents is a fundamental aspect of sustainable urban planning and management. This paper proposes a metric of effective green equivalent (EGE), which is defined as the area of green space multiplied by corrected coefficients of quality and accessibility. Based on the EGE values of individual residents, two city-level indicators are developed: (1) average EGE, which refers to the average level of EGE values of all urban residents within the urban boundary; and (2) an inequality coefficient, which measures the inequality of EGE distribution across the urban area. Three indicators (EGE, average EGE, and the inequality coefficient) were used to measure the real green spaces of the urban residents of Beijing, China. The results showed that the EGE values for individual residents in Beijing follow a normal distribution. The average EGE value is 355.49 ha per resident and the inequality coefficient value is calculated to be 0.24 , indicating that the current public green spaces of Beijing can basically meet residents' requirements. These indicators can thus be applied to urban public green space planning practice.
\end{abstract}

(C) 2014 Elsevier Ltd. All rights reserved.

\section{Introduction}

Urban green spaces are an indispensable infrastructure in cities and can provide urban residents many essential benefits, including recreation, culture, and education (Bolund and Hunhammar, 1999; Cameron et al., 2012; Smith et al., 2013). Urban residents are entitled to the benefits of conveniently accessible green spaces (Bastian et al., 2012; Chiesura, 2004). Compared with private green spaces, public green spaces (PGS) should play a major role in the urban green system, especially in more densely populated urban areas (Coolen and Meesters, 2012; Niemelä, 2014). As public goods, PGS are important sources of urban residents' environmental welfare, and the quantity of PGS has a huge influence on their quality of life (van Kamp et al., 2003).

A series of measurement approaches have been used to quantify the PGS resources of urban residents. Most of these have simply focused on the total and per capita area to measure the richness of PGS in cities. Moreover, this indicator-per capita area-is inconsistent with the concept of urban PGS as a public good. It is instead incorrectly based on the concept of personal property, which by default divides PGS into equal independent areas in line with the number of residents, and then distributes the PGS throughout the urban system accordingly (Lauf et al., 2014; Witte and Geys, 2011).

\footnotetext{
* Corresponding author. Tel.: +86 1062849110 .

E-mail addresses: liujingru@rcees.ac.cn, dylanyao@126.com (J. Liu).
}

However, while residents are equally entitled to all of the PGS resources within an urban boundary, factors such as quality and accessibility affect the real benefits acquired (Gupta et al., 2012; Wright Wendel et al., 2012). Therefore, the total area of PGS, without considering quality and accessibility, is an overly optimistic measurement.

Accessibility is thus important. The green area within an accepted range, commonly within walking distance from residential areas, is generally used as a measure of the available PGS resources (Langford et al., 2008; Schipperijn et al., 2010; Villeneuve et al., 2012). However, it may be necessary for multiple-level accessibility to be calculated to obtain the actual green area for each level of user (Barbosa et al., 2007; Wright Wendel et al., 2012). The quality of green space is also an important factor in the calculation of effective PGS (Romero et al., 2012), because high-quality PGS can provide many more benefits than low-quality areas (Tian et al., 2014). Thus, data on the effective area of PGS should be corrected by incorporating quality differences between green spaces (Wendel et al., 2011). For example, ecological green equivalent space is taken as the quality measure for green spaces with different vegetation covers (Liu et al., 2002). These measurements can more reliably quantify the effective urban PGS area from the perspectives of accessibility and quality.

There are few case studies of the integrated evaluation of the accessibility and quality of green spaces in relation to residential PGS resources. In this paper, we develop three new indicators of effective green equivalent (EGE), average EGE, and an inequality 
coefficient (IC), as supplements for the conventional measurement of green spaces. Section 2 describes the methodology of the proposed indicators. Section 3 documents a case study of Beijing to illustrate the use of these indicators, and Section 4 presents the results of this case study. Finally, Section 5 gives a brief discussion of the effectiveness of these indicators.

\section{Methodology}

\subsection{Effective green equivalent}

\subsubsection{Definition of EGE}

Here we develop an indicator for measuring the PGS resources that truly benefit every resident. For convenience, the PGS system is denoted as $\left\{g_{k}, k=1,2, \ldots, n\right\}$, where $g_{k}$ is the $k$ th green patch in $n$ independent green patches. Similarly, the population of urban residents is denoted as $\left\{p_{i}, i=1,2, \ldots, m\right\}$, where $p_{i}$ is the ith individual in all $m$ urban residents. We take green patch $g_{k}$ and resident $p_{i}$ as an example. Theoretically, the amount of PGS resources that $g_{k}$ provides for $p_{i}$ is equal to the area of $g_{k}$. In practice, the two factors of $g_{k}$, quality and accessibility, may weaken its effectiveness for $p_{i}$. Only when the quality, accessibility, and area of $g_{k}$ are all in ideal conditions are residents able to acquire maximal benefits. Therefore, the area of $g_{k}$ should be corrected by integrating its quality and accessibility factors in order to accurately measure the services or benefits that $g_{k}$ provides for $p_{i}$. This corrected area of green spaces is called the effective green equivalent (EGE).

The EGE that $g_{k}$ provides for $p_{i}$ can be expressed as

$\operatorname{EGE}\left(p_{i}, g_{k}\right)=S\left(g_{k}\right) \times q\left(g_{k}\right) \times a\left(g_{k}, p_{i}\right)$

where $S\left(g_{k}\right)$ denotes the area of $g_{k}$, and $q\left(g_{k}\right)$ and $a\left(g_{k}, p_{i}\right)$ are correction coefficients that quantify the performances of the quality and accessibility factors, respectively. If all of the green spaces are taken into consideration, then the total EGE of resident $p_{i}$ may be expressed as

$\operatorname{EGE}\left(p_{i}\right)=\sum_{k} \operatorname{EGE}\left(p_{i}, g_{k}\right)=\sum_{k} S\left(g_{k}\right) \times q\left(g_{k}\right) \times a\left(g_{k}, p_{i}\right)$

where $\operatorname{EGE}\left(p_{i}\right)$ quantifies the PGS that truly benefit resident $p_{i}$. The calculation of the two correction coefficients, $q\left(g_{k}\right)$ and $a\left(g_{k}, p_{i}\right)$, is described below.

\subsubsection{Quantification of $a\left(g_{k}, p_{i}\right)$}

We took $p_{i}$ and $g_{k}$ as examples to quantify $a\left(g_{k}, p_{i}\right)$, the correction coefficient based on accessibility. Accessibility is mainly determined by the least road distance $d\left(g_{k}, p_{i}\right)$, which is the minimum total length of all possible paths from $p_{i}$ residence to green patch $g_{k}$. When $d\left(g_{k}, p_{i}\right)=0$ (i.e., the place of residence adjoins the target green patch) then the accessibility is in an ideal state, denoting as $a\left(g_{k}, p_{i}\right)=1$. When $d\left(g_{k}, p_{i}\right)$ gradually increases within the tolerable daily walking range, the accessibility value will decrease steadily; when exceeding the threshold, the accessibility value will decline rapidly. If $d\left(g_{k}, p_{i}\right)$ keeps increasing, accessibility will enter a poor state and no longer be sensitive to distance, and theoretically, when $d\left(g_{k}, p_{i}\right)$ is infinite there is no accessibility at all [i.e., $\left.a\left(g_{k}, p_{i}\right)=0\right]$. These features of $a\left(g_{k}, p_{i}\right)$ are similar to the symmetrically rotated form of an S-shaped growth curve. Here, the formula of $a\left(g_{k}, p_{i}\right)$ is derived based on the classic Logistic Equation and by taking into account the boundary conditions, $0-1$. The correction coefficient based on accessibility is expressed as follows:

$a\left(g_{k}, p_{i}\right)=\left(1+\frac{1}{r_{1}}\right) \times\left(1-\frac{1}{1+r_{1} e^{-r_{2} d\left(g_{k}, p_{i}\right)}}\right)$

where $r_{1}$ and $r_{2}$ are positive parameters and are determined by the residents' experiences about accessibility.

\subsubsection{Quantification of $q\left(g_{k}\right)$}

When the quality of green patch $g_{k}$ is significantly poor, it is almost impossible for the residents to acquire benefits and this situation can be denoted as $q\left(g_{k}\right)=0$. However, it is difficult to determine what qualities are most desirable in PGS. In practice, green space $g_{0}$ can be pre-selected as a reference template that is able to provide the residents with satisfying recreation experience. Under this condition, $q\left(g_{0}\right)$ is set as 1 . The quality of other green patches can be evaluated by referring to the green space $g_{0}$. Here we adopt a normalized difference vegetation index (NDVI) to evaluate the quality of green spaces. The average NDVI over green patch $g_{k}$ is equal to $q\left(g_{k}\right)$, the correction coefficient based on quality, which is expressed as follows:

$q\left(g_{k}\right)=\frac{\int_{S\left(g_{k}\right)} \max (\mathrm{NDVI}, 0) \mathrm{d} s}{S\left(g_{k}\right)}$

where $\max (\mathrm{NDVI}, 0)$ denotes the maximum value between NDVI and 0 , ranging from 0 to 1 .

Substituting Eqs. (3) and (4) into Eq. (2), we calculate EGE as

$$
\begin{aligned}
\operatorname{EGE}\left(p_{i}\right)= & \sum_{k}\left[\left(1+\frac{1}{r_{1}}\right) \times\left(1-\frac{1}{1+r_{1} e^{-r_{2} d\left(g_{k}, p_{i}\right)}}\right)\right. \\
& \left.\times \int_{S\left(g_{k}\right)} \max (\mathrm{NDVI}, 0) \mathrm{d} s\right]
\end{aligned}
$$

\subsection{Average effective green equivalent}

A city-level indicator is defined to measure the average EGE of all residents within the city boundaries, termed the average effective green equivalent (AEGE). The value of AEGE equals the mean of all individual-resident's EGE and can be expressed as

$\mathrm{AEGE}=\frac{1}{m} \sum_{i} \operatorname{EGE}\left(p_{i}\right)$

where $m$ is the total number of urban residents.

Regardless of individual differences among residents, the higher a city's AEGE value is, the more PGS resources are available to its urban residents. The urban AEGE also follows the law of diminishing marginal utility. When AEGE exceeds a certain threshold, the utility growth acquired by a continuous increase of unit AEGE declines. Meanwhile, excessive PGS will occupy the space needed for other socio-economic activities, negatively affecting coordinated development of the city as a whole. Therefore, it is necessary to find out the residents' basic demand and utility saturation threshold.

\subsection{The inequality coefficient}

The inequality coefficient (IC) is proposed directly using the Gini coefficient in economics as a reference, and measuring the income inequality of residents. It is calculated by drawing the Lorenz curve (Dorfman, 1979). Here we replace income with the EGE of urban residents to derive the IC. It can be expressed as

IC $=\frac{1}{m}\left[m+1-2\left(\frac{\sum_{i}(m+1-i) \times \operatorname{EGE}\left(p_{i}\right)}{\sum_{i} \operatorname{EGE}\left(p_{i}\right)}\right)\right]$

where IC ranges from 0 to 1 and $\operatorname{EGE}\left(p_{i}\right), i=1$ to $m$, is indexed in non-decreasing order $\left[\operatorname{EGE}\left(p_{i}\right) \leq \operatorname{EGE}\left(p_{i+1}\right)\right]$.

The higher a city's IC value is, the more unequal the PGS distribution is among the urban residents. A set of reference values should be established to explain the meaning of IC values. For example, we can directly adopt the reference values of the Gini coefficient where $<0.2$ is basically equal, $0.2-0.4$ is an acceptable range, and $>0.4$ is highly unequal. 


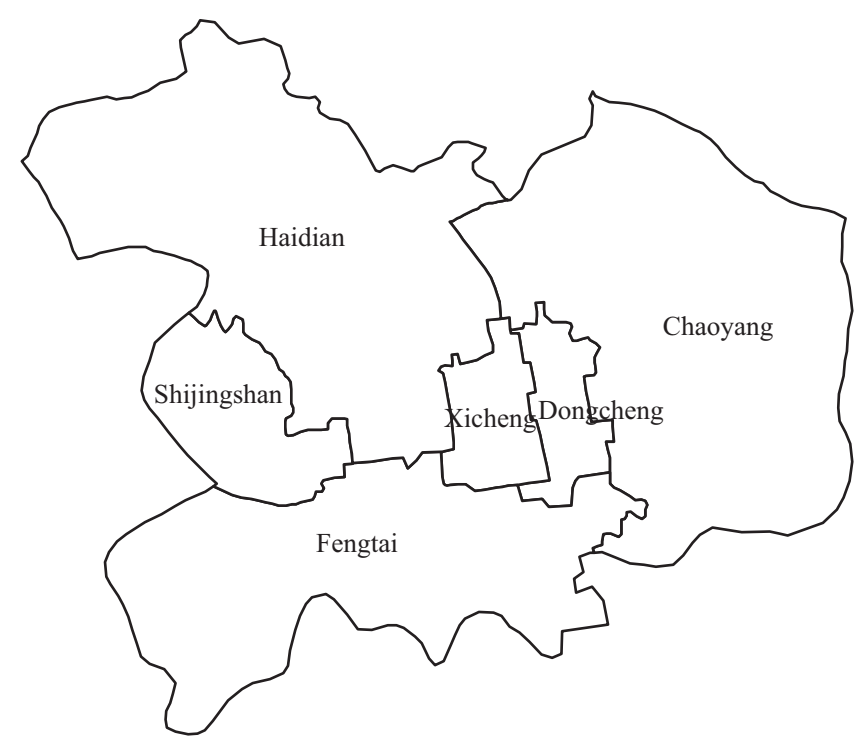

Fig. 1. The six major urban districts of Beijing.

\section{Case study}

\subsection{Study site}

Beijing has undergone significant economic development and rapid urban expansion over the past 30 years. The population within the major urban districts reached 11,683,200 in 2010 (BMBS, 2011). Private green spaces are still relatively rare, however, so the provision of green space ecosystem services mainly depends on PGS. Our research was conducted in 2010 and is confined to six major urban districts, i.e., Dongcheng, Xicheng, Chaoyang, Haidian, Fengtai, and Shijingshan (Fig. 1). For the PGS system, we included the green parks within $10 \mathrm{~km}$ of the major urban district boundary, as accessibility is quite low beyond this distance.

\subsection{Data sources}

This case study used five data sources: (1) the sixth China Population Census which provided 2010 population data grouped by township (town and sub-district) in six major urban districts of Beijing (OSPCBM, 2012). (2) geographic distribution data on urban residential communities, which were obtained from Beijing municipal government departments. From these data community population distributions were derived by distributing the total population of sub-districts according to community area proportions (Langford et al., 2008); (3) geographical distribution of PGS obtained directly from the latest PGS planning reports; (4) green spaces NDVI derived from satellite data; and (5) road network data for the accessibility calculation, obtained from a commercial map company. One hundred internet questionnaires were distributed to residents in order to investigate experiences of distance and accessibility. The values of $r_{1}$ and $r_{2}$ in Eq. (3) were estimated to be 10.15 and 0.46 , respectively. Fig. 2 shows the curve of the correction coefficient based on accessibility.

\section{Results}

Fig. 3 shows the frequency distribution of the EGE values. The sample size of the EGE values is equal to the population of urban residents; 11,683,200 within the study boundary in 2010 . A Kolmogorov-Smirnov test showed that EGE values followed a normal distribution ( $p$-value $=0.7274$ ). This suggests that $68.2 \%$ of city residents in Beijing can access a moderate level of green space

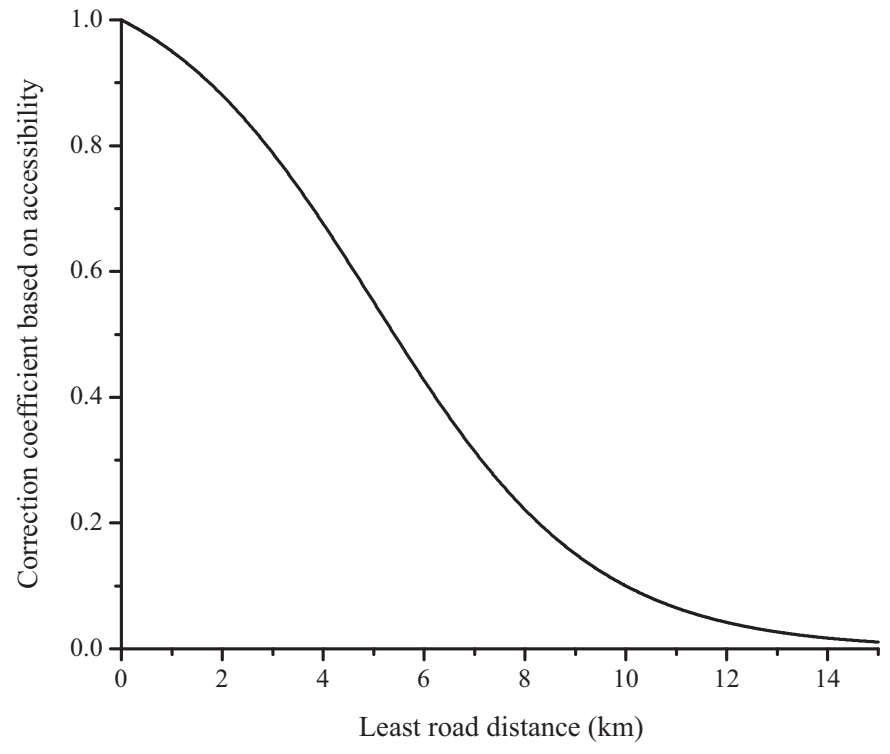

Fig. 2. Curve of the correction coefficient based on accessibility. The correction coefficient ranges from 0 to 1 and is determined by the least road distance, which is the minimal length of all possible road paths from the residence of urban resident to the target green patch.

(ranging from 205.52 to $505.46 \mathrm{ha}$ ), and that the remaining residents had access to less ( $<205.52 \mathrm{ha}$ ) or more $(>505.46 \mathrm{ha})$ green space. This is an expected result, as the case study surveys the whole population of Beijing rather than a small sample of urban residents. Whether other cities in China have a similar frequency distribution needs to be further investigated.

Table 1 lists the common statistical parameters derived from the EGE values in the major urban districts of Beijing. The mean represents one city-level indicator, AEGE. At the city scale, the AEGE value of Beijing is 355.49 ha per resident, approximately half of the maximum value. This value is far below the total area (4801.44 ha), but far above the per capita area $\left(4.11 \mathrm{~m}^{2}\right)$. Of the six major urban districts, Fengtai has significantly smaller values than other districts, and the AEGE value of Fengtai is less than half of the city

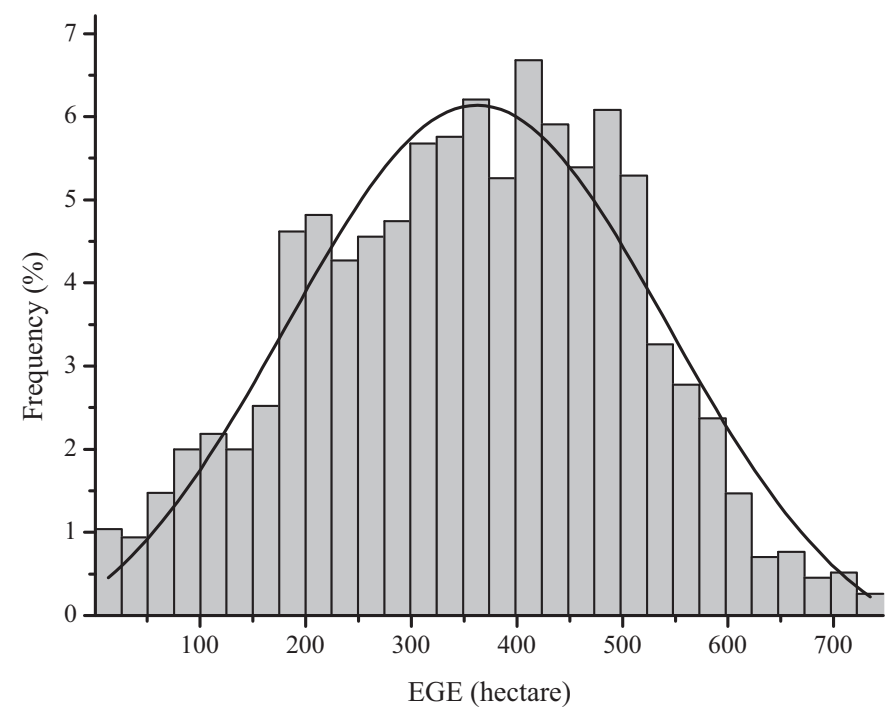

Fig. 3. Frequency distribution of the EGE values. The EGE, effective green equivalent, measures the public green space that truly benefits each resident in Beijing; it is divided into 30 equal intervals from minimal to maximal values for frequency analysis. The curve is a normal distribution curve based on the mean and standard deviation of the EGE values. 
Table 1

Statistical parameters of the EGE values in the urban districts of Beijing (2010, hectare).

\begin{tabular}{|c|c|c|c|c|c|}
\hline Urban districts & Maximum & Minimum & Mean & Median & Standard deviation \\
\hline Dongcheng & 584.46 & 281.00 & 435.92 & 460.77 & 74.64 \\
\hline Xicheng & 635.93 & 288.65 & 403.13 & 386.18 & 69.82 \\
\hline Chaoyang & 746.92 & 65.58 & 411.00 & 424.52 & 141.12 \\
\hline Fengtai & 436.08 & 8.97 & 171.82 & 179.59 & 77.33 \\
\hline Shijingshan & 551.59 & 168.14 & 310.32 & 286.26 & 114.15 \\
\hline Haidian & 656.13 & 0.83 & 381.50 & 387.00 & 142.19 \\
\hline Total & 746.92 & 0.83 & 355.49 & 362.98 & 149.97 \\
\hline
\end{tabular}

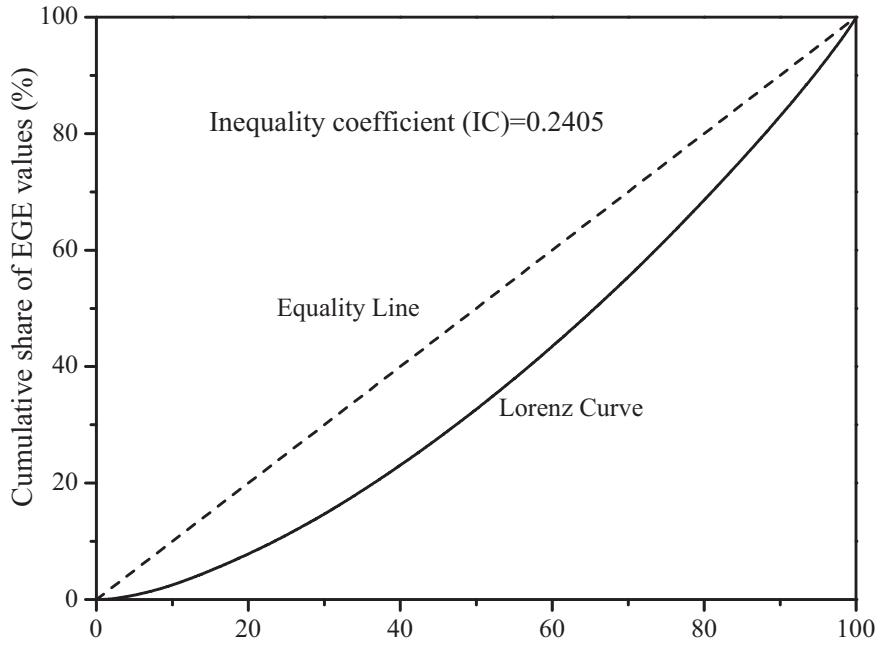

Cumulative share of residents from lowest to highest EGE values (\%)

Fig. 4. The inequality coefficient (IC) and the corresponding Lorenz curve. The dotted straight line represents an ideal state of resource distribution in absolute equality-the so-called equality line. The solid curved line represents the Lorenz curve corresponding to EGE. IC is the ratio of the area between equality line and Lorenz curve to the total triangle area below equality line.

average. From the perspective of PGS, this result implies that the residents in Fengtai district have a relatively poor level of urban environmental welfare. The minimum values (Table 1) are also of great importance because they indicate how serious the situation is if actual PGS fails to meet minimum environmental welfare levels. In Haidian and Fengtai districts, a few residents have access to much lower levels of PGS resources than the AEGE value; these places should build green parks in the future. Across the city, the EGE values did not, however, deviate much from the mean values (Table 1), indicating that the distribution of EGE values in individual districts is relatively compact, as confirmed in the frequency histogram.

The IC, the other city-level indicator, was also calculated in this case study. The IC value and corresponding Lorenz curve are shown in Fig. 4. The line at a $45^{\circ}$ angle-the so-called equality line-indicates the situation where the PGS distribution is absolutely equal for every resident. The Lorenz curve of the EGE values in Beijing deviates slightly from the equality line. The Lorenz curve is relatively continuous and smooth, which is because of the large sample size and the normal frequency distribution. The IC value is calculated to be 0.24 based on the Lorenz curve (Fig. 4). It is far below the Gini coefficient of residents' income during the same period (Chi, 2012), indicating that the degree of PGS inequality in Beijing is within an acceptable range.

\section{Discussion}

Applications. The indicators proposed in this study can be applied in urban PGS planning practice. The indicators are able to provide urban planners with quantifiable goals that are sensitive to feedbacks and recognition from urban residents (Weber, 2003; Zylicz, 2007). Planners can also use the indicators to measure PGS and clarify the gaps between goals and the current situation (Moldan et al., 2012; Tanguay et al., 2010). The distribution of indicator values will provide valuable information for the planning process (La Rosa, 2014). For example, the areas where residents have poor PGS resources can be targeted as sites for new green parks. The indicators can also be used to measure the PGS of other cities similar to Beijing. Comparison between cities could reveal more information. For example, these could be used to test whether the frequency distribution of other cities' EGE values did or did not follow a normal distribution. Furthermore, the indicators can be integrated into a quantitative planning model (Campbell 1996; Gaube and Remesch, 2013; Weber, 2003). With these indicators, urban planners are able to carry out smarter and more efficient urban PGS planning.

Recommendations. The indicators can comprehensively measure the situation of urban PGS resources. The EGE not only integrates the factors (accessibility and quality of green spaces) into the measurement of PGS resources, but also implicitly includes the spatial distribution of urban residents and PGS. The calculation of EGE also factors residents' experiences in daily life, such as with the estimation of parameters in the accessibility formula. Crossscale measurements, including individual and city-level indicators, are other advantages of our methodology. EGE measures the PGS resources of individual residents while the city-level indicators, AEGE and IC, give an overall assessment of the whole city. This hierarchy provides users with more flexibility, depending on their specific intentions.

Limitations. The calculation methods for the indicators were simplified in the study. For example, only NDVI has been considered in the quality assessment of PGS. In fact, PGS quality is also determined by other factors such as landscape integrity, the impact of interesting or innovative designs, and residents' preferences. Similarly, there remains a certain degree of simplification in the accessibility assessment. In the case study of Beijing, only the road network has been considered, while the impact of other transportation infrastructure, such as bus and subway routes, are ignored. Moreover, public transport routes have a high impact on access to PGS (Qureshi et al., 2014; Wright Wendel et al., 2012). Additionally, our parameters were estimated based on a relatively small survey sample. In future studies, the calculation methods should be improved, especially for the quality and accessibility of green spaces.

\section{Acknowledgments}

The authors thank Bin Chen, Hongxiao Liu, Ye Yuan for their valuable suggestions. This research was supported by National Natural Science Foundation of China (No. 71033005). 


\section{References}

Barbosa, O., Tratalos, J.A., Armsworth, P.R., Davies, R.G., Fuller, R.A., Johnson, P., Gaston, K.J., 2007. Who benefits from access to green space? A case study from Sheffield, UK. Landsc. Urban Plan. 83, 187-195.

Bastian, O., Haase, D., Grunewald, K., 2012. Ecosystem properties, potentials and services-the EPPS conceptual framework and an urban application example. Ecol. Indic. 21, 7-16.

BMBS, 2011. Beijing Statistical Yearbook 2011. China Statistics Press, Beijing, China.

Bolund, P., Hunhammar, S., 1999. Ecosystem services in urban areas. Ecol. Econ. 29, 293-301.

Cameron, R.W.F., Blanuša, T., Taylor, J.E., Salisbury, A., Halstead, A.J., Henricot, B., Thompson, K., 2012. The domestic garden-its contribution to urban green infrastructure. Urban For. Urban Green. 11, 129-137.

Campbell, S., 1996. Green cities, growing cities, just cities? Urban planning and the contradictions of sustainable development. J. Am. Plan. Assoc. 62, 296-312.

Chi, W., 2012. Capital income and income inequality: evidence from urban China. J. Comp. Econ. 40, 228-239.

Chiesura, A., 2004. The role of urban parks for the sustainable city. Landsc. Urban Plan. 68, 129-138.

Coolen, H., Meesters, J., 2012. Private and public green spaces: meaningful but different settings. J. Hous. Built Environ. 27, 49-67.

Dorfman, R., 1979. A formula for the Gini coefficient. Rev. Econ. Stat. 61, 146-149.

Gaube, V., Remesch, A., 2013. Impact of urban planning on household's residential decisions: an agent-based simulation model for Vienna. Environ. Model. Softw. 45, 92-103.

Gupta, K., Kumar, P., Pathan, S.K., Sharma, K.P., 2012. Urban neighborhood green index-a measure of green spaces in urban areas. Landsc. Urban Plan. 105, 325-335.

La Rosa, D., 2014. Accessibility to greenspaces: GIS based indicators for sustainable planning in a dense urban context. Ecol. Indic. 42, 122-134.

Langford, M., Higgs, G., Radcliffe, J., White, S., 2008. Urban population distribution models and service accessibility estimation. Comput. Environ. Urban Syst. 32, 66-80.

Lauf, S., Haase, D., Kleinschmit, B., 2014. Linkages between ecosystem services provisioning, urban growth and shrinkage-a modeling approach assessing ecosystem service trade-offs. Ecol. Indic. 42, 73-94.

Liu, Y., Ming, D., Yang, J., 2002. Optimization of land use structure based on ecological GREEN equivalent. Geo-spatial Inf. Sci. 5, 60-67.

Moldan, B., Janoušková, S., Hák, T., 2012. How to understand and measure environmental sustainability: indicators and targets. Ecol. Indic. 17, 4-13.
Niemelä, J., 2014. Ecology of urban green spaces: the way forward in answering major research questions. Landsc. Urban Plan. 125, 298-303.

OSPCBM, 2012. Tabulation on the 2010 Population Census of Beijing Municipality (Town and Sub-district Volume). China Statistics Press, Beijing, China.

Qureshi, S., Haase, D., Coles, R., 2014. The Theorized Urban Gradient(TUG) method-a conceptual framework for socio-ecological sampling in complex urban agglomerations. Ecol. Indic. 36, 100-110.

Romero, H., Vásquez, A., Fuentes, C., Salgado, M., Schmidt, A., Banzhaf, E., 2012. Assessing urban environmental segregation (UES). The case of Santiago de Chile. Ecol. Indic. 23, 76-87.

Schipperijn, J., Stigsdotter, U.K., Randrup, T.B., Troelsen, J., 2010. Influences on the use of urban green space-a case study in Odense, Denmark. Urban For. Urban Green. 9, 25-32.

Smith, L.M., Case, J.L., Smith, H.M., Harwell, L.C., Summers, J.K., 2013. Relating ecoystem services to domains of human well-being: foundation for a U.S. index. Ecol Indic. 28, 79-90.

Tanguay, G.A., Rajaonson, J., Lefebvre, J.-F., Lanoie, P., 2010. Measuring the sustainability of cities: an analysis of the use of local indicators. Ecol. Indic. 10, 407-418.

Tian, Y., Jim, C.Y., Wang, H., 2014. Assessing the landscape and ecological quality of urban green spaces in a compact city. Landsc. Urban Plan. 121, 97-108.

van Kamp, I., Leidelmeijer, K., Marsman, G., de Hollander, A., 2003. Urban environmental quality and human well-being: towards a conceptual framework and demarcation of concepts; a literature study. Landsc. Urban Plan. 65, 5-18.

Villeneuve, P.J., Jerrett, M.G., Su, J., Burnett, R.T., Chen, H., Wheeler, A.J., Goldberg, M.S., 2012. A cohort study relating urban green space with mortality in Ontario, Canada. Environ. Res. 115, 51-58.

Weber, C., 2003. Interaction model application for urban planning. Landsc. Urban Plan. 63, 49-60.

Wendel, H.E.W., Downs, J.A., Mihelcic, J.R., 2011. Assessing equitable access to urban green space: the role of engineered water infrastructure. Environ. Sci. Technol. 45, 6728-6734.

Witte, K.D., Geys, B., 2011. Evaluating efficient public good provision: theory and evidence from a generalised conditional efficiency model for public libraries. J. Urban Econ. 69, 319-327.

Wright Wendel, H.E., Zarger, R.K., Mihelcic, J.R., 2012. Accessibility and usability: green space preferences, perceptions, and barriers in a rapidly urbanizing city in Latin America. Landsc. Urban Plan. 107, 272-282.

Zylicz, T., 2007. Sustainability indicators: an economist's view. In: Hák, T., Moldan, B. Dahl, A.L. (Eds.), Sustainability Indicators: A Scientific Assessment. Island Press, Washington, USA, pp. 97-105. 